\title{
Effect of Acicular Ferrite on Cracking Sensibility in the Weld Metal of $0690+0550$ High Strength Steels
}

\author{
Lei ZHANG, Yajiang LI, Juang WANG and Qinglei JIANG \\ Key Lab for Liquid-Solid Structural Evolution and Processing of Materials (Ministry of Education), Shandong University, \\ Jinan 250061, Shandong province, P. R. China. E-mail: yajli@sdu.edu.cn
}

(Received on February 21, 2011; accepted on April 7, 2011)

\begin{abstract}
High strength steels $0690+0550$ were welded using three different welding wires without preheating by gas shielded arc welding process. Microstructural characteristics of weld metals and nucleation mechanism of acicular ferrite were investigated by means of scanning electron microscope (SEM), energy dispersive spectrum (EDS) and transmission electron microscope (TEM). The straight Y-groove test and impact test were employed to assess cracking resistance and impact toughness of joints. Results indicated that the addition of $\mathrm{Ti}$ and $\mathrm{Cr}$ in the MK·G60-1 weld metal suppressed the formation of pro-eutectoid ferrite and ferrite side plate and contributed to the formation of acicular ferrite. The inclusions composed of ( $\mathrm{Ti}, \mathrm{Mn}$ ) oxides and $\mathrm{Mn}, \mathrm{Cu}$ sulfides became nucleation sites of primary acicular ferrite. Secondary acicular ferrites were nucleated on some pre-existing ferrite laths. Impact toughness and cracking resistance were enhanced with the increase of acicular ferrite in the weld metal.
\end{abstract}

KEY WORDS: low alloy high strength steels; undermatched wires; crack; impact toughness; acicular ferrite.

\section{Introduction}

Performance of weld metal depends on its microstructure which is influenced by chemical composition of weld metal and welding parameters. In order to gain welded joints of low alloy high strength steels with satisfactory mechanical properties and cracking resistance, it is necessary for weld metal to obtain high volume fraction of acicular ferrite. Fine acicular ferrite containing high density of dislocations is the expected microstructure in weld metal. High-angle boundaries among ferrite laths act as an obstacle to cleavage propagation, forcing cleavage crack to change the microscopic plane of propagation. ${ }^{1,2)}$ For this reason, more acicular ferrite in weld metal is of the utmost importance to reach a weld joint with optimal combination of strength and toughness.

Oxide metallurgy has been employed in improvement of steel quality and toughness of heat affected zones (HAZs) of linepipe steels. ${ }^{3,4)}$ Oxides and sulfides can become nucleation sites of acicular ferrite. Alloying elements in welding wire and base metal play a significant role in microstructural control, especially in acicular ferrite transformation. ${ }^{5)} \mathrm{Ti}, \mathrm{Cu}$ and $\mathrm{Mn}$ in weld metal and $\mathrm{O}$ from shielding gas are beneficial to the formation of acicular ferrite. Acicular ferrite transformation occurs in a narrow cooling rate range while martensite or pro-eutectoid ferrite can form below or above transformation temperature of acicular ferrite, thus welding process must be precisely controlled to favor formation of acicular ferrite. Some studies have investigated the controlling of oxides and sulfides in steelmaking process and their effects on nucleation of acicular ferrite in molten steel or in
HAZs of linepipe steels. ${ }^{6-8)}$ The present work attempts to correlate weld heat input, formation of acicular ferrite with Charpy impact properties of weld metal.

Preheating treatment is a measure to avoid crack initiation, but it could bring down the productivity efficiency, increase welding costs and make it difficult to guarantee the welding quality with the change of preheating temperature.9) Therefore, it is necessary to investigate how to obtain joints with excellent properties without preheating by controlling welding parameters.

In this work, considerable efforts have been undertaken to investigate the cracking tendency of Q690+Q550 joints of different welding wires without preheating treatment and analyze the effect of welding wires on toughness and microstructure in weld metal. Microstructure and nucleation mechanism of acicular ferrite were studied by SEM, EDS and TEM.

\section{Materials and Experimental Procedure}

The base metals were Q550 steel produced by thermo mechanical controlled rolling process and Q690 quenchedtempered steel. The suffix numbers 690 and 550 which denoted minimum yield strengths were $690 \mathrm{MPa}$ and $550 \mathrm{MPa}$, respectively. Three strength match welding wires of $1.2 \mathrm{~mm}$ in diameter (ER50-6 wire, MK.G60 wire and MK·G60-1 wire) were employed during welding. The asdeposited tensile strengths with three wires were above $550 \mathrm{MPa}, 600 \mathrm{MPa}$ and $650 \mathrm{MPa}$, respectively. The respective chemical compositions and mechanical properties of steels and welding wires used in the test were listed in 
Tables 1 and 2. The welding process was accomplished in the workshop with no preheating treatment by NBC-500 gas shielded arc welding machine. The shielding gas was $80 \% \mathrm{Ar}+20 \% \mathrm{CO}_{2}$. The welding parameters were shown in Table 3.

The straight Y-groove test was conducted to evaluate susceptibility to cold cracking (hydrogen and weld metal solidification cracking) of the test weldments. The test procedure conformed to standard AWS 4.0: 2007, while the only difference was that the groove shape of test plates changed into straight Y-type. Plates of $200 \mathrm{~mm} \times 75 \mathrm{~mm} \times 20 \mathrm{~mm}$ with a single V-groove $\left(30^{\circ}\right)$ were welded without preheating. The weldments were left to cool down in air at ambient temperature for minimum period of $48 \mathrm{~h}$. Then surface crack and section crack were inspected and calculated. For section crack examination, each weld bead was transversely sectioned into five parts with even length. The section crack analysis was based on equation given below:

$$
\mathrm{C}_{\mathrm{S}}=\frac{\sum H_{S}}{\sum H} \times 100 \%
$$

where $H_{s}$ was the height of crack in each sectioned specimen, mm; $H$ was the minimum thickness of each weld bead, $\mathrm{mm}$.

Plates of $300 \mathrm{~mm} \times 148 \mathrm{~mm} \times 20 \mathrm{~mm}$ were prepared for mechanical properties evaluation. Before welding, single

Table 1. Chemical composition of steels and welding wires used in the test.

\begin{tabular}{cccccccccccc}
\hline \multirow{2}{*}{ Materials s } & \multicolumn{10}{c}{ Chemical composition (wt. \%) } \\
\cline { 2 - 10 } & $\mathrm{C}$ & $\mathrm{Si}$ & $\mathrm{Mn}$ & $\mathrm{Cr}$ & $\mathrm{Mo}$ & $\mathrm{Ni}$ & $\mathrm{Ti}$ & $\mathrm{S}$ & $\mathrm{P}$ & $\mathrm{Fe}$ \\
\hline Q550 & 0.079 & 0.372 & 1.763 & - & - & - & - & 0.02 & 0.011 & balance \\
Q690 & 0.089 & 0.237 & 1.47 & 0.426 & 0.323 & 0.258 & 0.10 & 0.009 & 0.021 & balance \\
ER50-6 & 0.07 & 0.91 & 1.48 & - & - & - & - & 0.011 & 0.011 & balance \\
MK·G60 & 0.09 & 0.75 & 1.85 & - & 0.35 & - & - & 0.019 & 0.018 & balance \\
MK·G60-1 & 0.09 & 0.69 & 1.64 & 0.08 & - & - & 0.11 & 0.010 & 0.015 & balance \\
\hline
\end{tabular}

Table 2. Mechanical properties of steels and welding wires used in the test.

\begin{tabular}{ccccc}
\hline \multirow{2}{*}{ Materials } & \multicolumn{4}{c}{ Mechanical properties } \\
\cline { 2 - 5 } & $\begin{array}{c}\text { Yield strength } \\
(\mathrm{MPa})\end{array}$ & $\begin{array}{c}\text { Tensile strength } \\
(\mathrm{MPa})\end{array}$ & $\begin{array}{c}\text { Elongation } \\
(\%)\end{array}$ & $\begin{array}{c}\text { Impact energy } \\
(\mathrm{J})\end{array}$ \\
\hline Q550 & 550 & 756 & $\geq 16$ & $\geq 40\left(-20^{\circ} \mathrm{C}\right)$ \\
Q690 & 690 & 835 & $\geq 14$ & $\geq 40\left(-20^{\circ} \mathrm{C}\right)$ \\
ER50-6 & 459 & 561 & 24 & $84\left(-29^{\circ} \mathrm{C}\right)$ \\
MK·G60 & 575 & 635 & 25 & $90\left(-20^{\circ} \mathrm{C}\right)$ \\
MK·G60-1 & 600 & 665 & 23 & $60\left(-40^{\circ} \mathrm{C}\right)$ \\
\hline
\end{tabular}

Table 3. Welding parameters used in the test.

\begin{tabular}{ccccccc}
\hline & \multicolumn{5}{c}{ Welding parameters } \\
\cline { 2 - 7 } $\begin{array}{c}\text { Welding } \\
\text { method }\end{array}$ & $\begin{array}{c}\text { Welding } \\
\text { current } \\
(\mathrm{A})\end{array}$ & $\begin{array}{c}\text { Welding } \\
\text { voltage } \\
(\mathrm{V})\end{array}$ & $\begin{array}{c}\text { Welding } \\
\text { speed } \\
\left(\mathrm{cm} \cdot \mathrm{s}^{-1}\right)\end{array}$ & $\begin{array}{c}\text { Gas flow } \\
\left(\mathrm{L} \cdot \mathrm{min}^{-1}\right)\end{array}$ & $\begin{array}{c}\text { Ambient } \\
\text { temperature } \\
\left({ }^{\circ} \mathrm{C}\right)\end{array}$ & $\begin{array}{c}\text { Relative } \\
\text { humidity } \\
(\mathrm{pct})\end{array}$ \\
\hline $\begin{array}{c}\text { Gas shielded } \\
\text { arc welding }\end{array}$ & $260-310$ & $29-31$ & $0.4-0.9$ & $18-20$ & 24 & 80 \\
\hline
\end{tabular}

"V" groove $35^{\circ}$ was made in the base plates. Standard Charpy V-notch specimens (with a $(10 \times 10) \mathrm{mm}^{2}$ section, a central $45^{\circ} \mathrm{V}$-notch of $2 \mathrm{~mm}$ depth and a $0.25 \mathrm{~mm}$ notch root radius) with their notch perpendicular to the long transverse orientation were tested with standard ISO 9016:2001 using an instrumented $300 \mathrm{~J}$ capacity impact tester at temperature $0^{\circ} \mathrm{C}$.

The welded joints were sliced and machined to the required dimensions $(20 \mathrm{~mm} \times 10 \mathrm{~mm} \times 25 \mathrm{~mm})$ for $\mathrm{SEM}$ observation. After being polished and etched with 5\% Nital the specimens were examined and analyzed by JSM6610LV SEM and Oxford INCA EDS system. Some thin slice samples were cut from weld metal and abraded into less than $50 \mu \mathrm{m}$ thickness then prepared as thin film samples by electrolyzing corrosion for TEM observation performed on $\mathrm{H}-800$ instrument.

\section{Results and Discussion}

\subsection{Effect of Heat Input on Welding Crack}

The straight Y-groove test was employed to investigate the effect of heat input on cold cracking susceptibility with different wires. Formulating heat input must accord with both cracking resistance capability of welded joint and toughness requirements of heat affected zone. From the cracking resistance point of view, cooling rate should be slower while from the prevention of embrittlement standpoint, cooling rate should be faster. Therefore, cooling rates must be taken into account and then the range of heat input used in this test was from $11 \mathrm{~kJ} / \mathrm{cm}$ to $20 \mathrm{~kJ} / \mathrm{cm}$. The welded joints with two wires were free of surface crack. The effects of heat input and welding wires on section crack ratio are illustrated in Figs. 1(a) and 1(b).

It can be seen in Fig. 1(a) that when ER50-6 wire was adopted, crack ratio showed a trend of first decrease and then increase with the increase of heat input. Similar variation of crack ratio with heat input could be noticed in welding joints with $\mathrm{MK} \cdot \mathrm{G} 60-1$ wire and $\mathrm{MK} \cdot \mathrm{G} 60$ wire. Meanwhile the crack ratio of joints with $\mathrm{MK} \cdot \mathrm{G} 60-1$ wire was lower than those of ER50-6 wire and MK·G60 wire no matter which heat input, low, intermediate or high level was used. Fig. 1(b) indicates that welded joint with $\mathrm{MK} \cdot \mathrm{G} 60-1$ wire exhibits better cracking resistance than those of ER50-6 wire and MK·G60 wire.

Ren ${ }^{10)}$ pointed out that it is necessary to increase the contents of alloying elements in welding wire with the increase of welding heat input. Therefore, for welding wires with fewer alloying elements (ER50-6 wire and MK·G60 wire) many attentions should be paid to avoid high heat input. In fact, the influence of heat input on crack only indirectly presents on microstructure. Different heat inputs and welding wires contributed to the discrepancy in microstructure and further influenced the crack ratio. Thus it can be concluded that choosing appropriate heat input level and welding wire could raise cracking resistance of welded joint.

\subsection{Toughness and Microstructure in Weld Metal}

Results of the Charpy impact test are shown in Table 4. It is clear that the impact toughness of weld metal with MK'G60-1 wire is larger than that of ER50-6 wire. The higher impact energy means that more energy crack propa- 

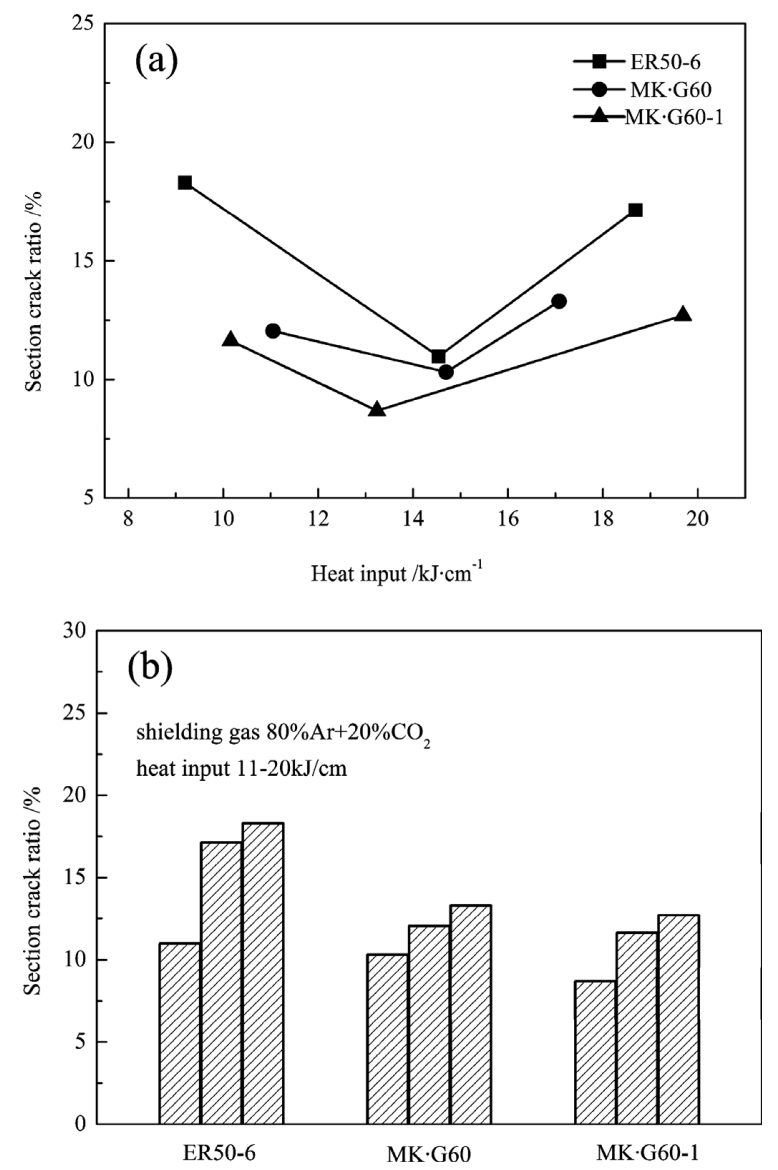

Fig. 1. Effect of (a) welding heat input and (b) welding wires on crack ratio.

Table 4. Experimental results of impact test for Q550+Q690 joints at $0^{\circ} \mathrm{C}$.

\begin{tabular}{ccccc}
\hline \multirow{2}{*}{ Welding wires } & \multicolumn{4}{c}{ Impact energy (J) } \\
\cline { 2 - 5 } & No. 1 & No. 2 & No. 3 & Average \\
\hline ER50-6 & 108 & 127 & 104 & 113 \\
MK·G60-1 & 146 & 142 & 129 & 139 \\
\hline
\end{tabular}

gation must be required and can contribute to low cracking sensibility.

The microstructure morphology of weld metals observed by SEM is depicted in Fig. 2. The microstructure of ER506 weld metal was a mixture of acicular ferrite (AF), proeutectoid ferrite (PF), ferrite side plate (FSP), and some fractions of bainite microstructure, as shown in Fig. 2(a). The formation of relatively coarse pro-eutectoid ferrite and ferrite side plate is considered detrimental to toughness because pro-eutectoid ferrite distributed on the boundary of prior austenite and parallel laths of ferrite side plate growing into grains provide preferential crack propagation routes. Once crack initiates it will propagate fast along the lowangle boundaries resulting in low toughness.

Figure 2(b) shows the microstructure in weld metal with MK.G60-1 wire. There is a significant amount of fine acicular ferrite and some small amounts of bainite. The increase of $\mathrm{Ti}$ and $\mathrm{Cr}$ content in the weld metal leads to more acicular ferrite and finer microstructure. The fine-grained interlocking acicular ferrite and its disordered laths arrangement can effectively impede the propagation of crack. As a result
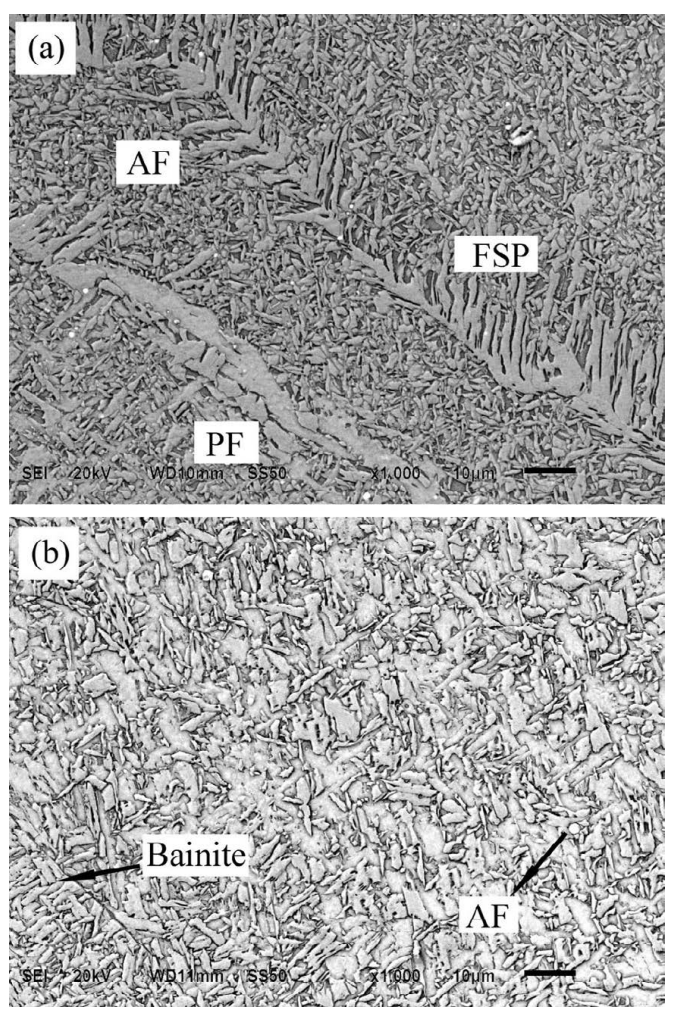

Fig. 2. Microstructure in weld metals with: (a) ER50-6 wire and (b) MK·G60-1 wire.

more energy is required for crack propagation contributing to high toughness. The acicular ferrite nucleates on inclusions inside prior austenite grains during the $\gamma \rightarrow \alpha$ transformation. Whether the interwoven acicular ferrite or sheaf morphology of bainite ferrite is formed would be determined by the competition of ferrite nucleation sites between prior austenite grain boundaries and non-metallic inclusions within prior austenite grains. ${ }^{11)}$

The transformation of acicular ferrite takes place at intermediate temperatures and cooling rates. The high heat input corresponding to slow cooling rate offers sufficient time to pass into the high temperature transformation region of austenite. Hence, the diffusion of carbon has become favorable at high temperature and facilitates the formation of coarse pro-eutectoid ferrite or polygonal ferrite. When low heat input is applied, short time at high temperature is taken for the formation of acicular ferrite and then it is favorable for the presence of some undesirable hardening phases (martensite). In a word, the formation of acicular ferrite depends on chemical composition of weld metal, amount of inclusions and prior austenite grain size. Therefore, to choose appropriate welding wire and heat input can assist in the formation of acicular ferrite.

\subsection{Nucleation of Acicular Ferrite}

Figure 3 shows the SEM image of acicular ferrite in weld metal with $\mathrm{MK} \cdot \mathrm{G} 60-1$ wire. Acicular ferrite is observed as a fine interlocking ferrite structure interspersed with microphases, which may be bainite microstructure (see Fig. 3(a)). Some globular inclusions are noticed in acicular ferrite, with diameter of $0.4-0.7 \mu \mathrm{m}$ and spacing more than $3 \mu \mathrm{m}$. A single inclusion acts as nucleation site of one primary acicular ferrite plate or multiple plates, and secondary acicular ferrite 

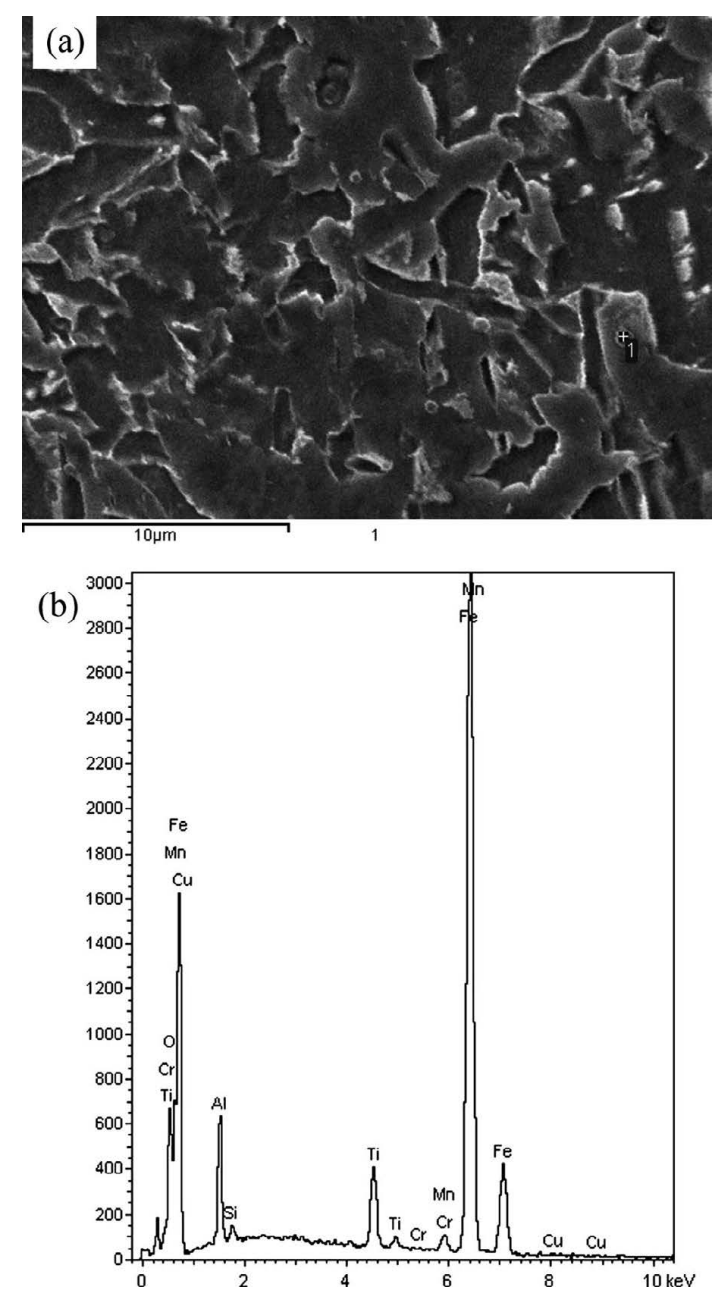

Fig. 3. (a) SEM micrograph of acicular ferrite in weld metal and (b) EDS analysis of the inclusion in acicular ferrite.

autocatalytically nucleates on interface between primary plate and austenite. As can also be observed in Fig. 3(a), the shape of some ferrite plates appears to be coarse rather than to be needle-like, but the width of ferrite plates is still not more than $5 \mu \mathrm{m}$. This is because the different ferrite morphologies cannot grow very far due to mutual restriction.

The globular inclusion is made up of the combination of $\mathrm{Ti}, \mathrm{Mn}$ and (Ti, Mn) oxides and small quantities of $\mathrm{Mn}$ and $\mathrm{Cu}$ sulfides, as illustrated by EDS in Fig. 3(b). Previous researchers have concluded that the inclusions such as $\mathrm{Ti}_{2} \mathrm{O}_{3}, \mathrm{TiO}, \mathrm{MnO}$ and $\mathrm{MnS}$ can act as active nucleation sites of acicular ferrite. ${ }^{12)}$ These inclusions may deplete elements such as Ti, Mn and Si from the austenite, which leads to a local increase of driving force for the nucleation of acicular ferrite on interface between inclusion and austenite. Owing to the difference in thermal expansion coefficients of austenite and inclusions, strain energy may develop near interface between inclusion and austenite, which may reduce activation energy for the nucleation. The inclusion with higher melting point $\left(\mathrm{Ti}_{2} \mathrm{O}_{3} 1842^{\circ} \mathrm{C}\right.$, $\left.\mathrm{TiO} 1750^{\circ} \mathrm{C}\right)$ often possesses higher surface energy leading to a reduction of nucleation energy barrier. Inclusions ( $\mathrm{TiO}, \mathrm{CuS}$ ) have good lattice match with ferrite can be potent nucleation sites.

The addition of $\mathrm{Ti}$ and $\mathrm{Cr}$ in weld metal has appreciable influence on the formation of acicular ferrite. $\mathrm{Cr}$ content in MK'G60-1 wire is $0.031 \%$. Jorge has concluded that an
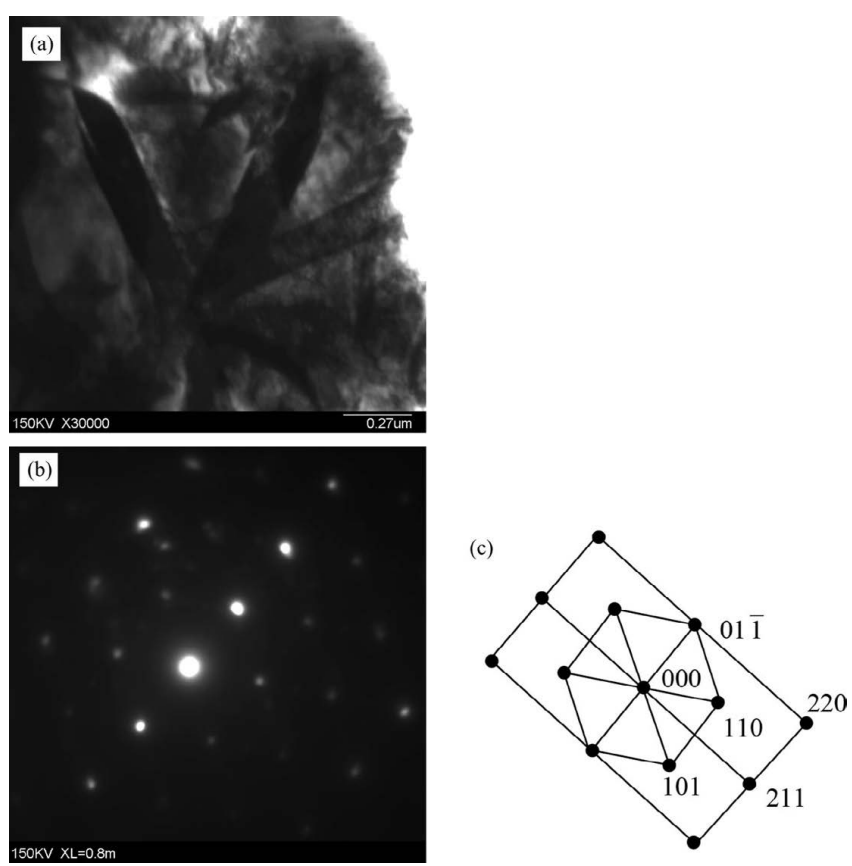

Fig. 4. Characteristics of weld metal with MK·G60-1 wire: (a) acicular ferrite morphology, (b) electron diffraction pattern and (c) schematic diagram, $B=[\overline{1} 11]$.

increase of $\mathrm{Cr}$ content can cause more acicular ferrite and a reduction of pro-eutectoid ferrite when $\mathrm{Cr}$ content is in the range of $0-2 \%{ }^{13)}$ It is observed that Ti-rich inclusions (especially $\mathrm{TiN}$ and $\mathrm{TiC}$ ) in the weld metal can be permanent traps for hydrogen atoms, which may lower the risk of cracking in sour environments. ${ }^{14)}$ Ti-containing oxides $\left(\mathrm{Ti}_{2} \mathrm{O}_{3}, \mathrm{TiO}, \mathrm{TiO}_{2}\right)$ are potent acicular ferrite nucleating agents. Due to cation vacancies $\mathrm{Ti}_{2} \mathrm{O}_{3}$ absorbs $\mathrm{Mn}$ in the vicinity and hence causes a dramatic depletion in $\mathrm{Mn}$ and an increase of driving force. $\mathrm{TiO}_{2}$ can release oxygen to decarburize adjacent weld metal, which is advantageous for nucleation of ferrite. ${ }^{11)}$

Nucleation of acicular ferrite occurs intra-granularly at inclusions or autocatalytically from pre-existing acicular ferrite laths. When MK·G60-1 wire was employed, Ti, Mn and $\mathrm{Si}$ assisted in the formation of active particles that become potent nucleation sites. Díaz-Fuentes has found that the formation of secondary plates nucleating on interface between ferrite and austenite plays a significant role in the formation of acicular ferrite. ${ }^{1)}$

TEM morphology, electron diffraction pattern and index schematic diagram of acicular ferrite in weld metal with MK. G60-1 wire, taken from [1111] direction, are shown in Figs. 4(a)-4(c). As can be observed in Fig. 4(a), the fine ferrite plates appear to be with widths of $0.15-0.2 \mu \mathrm{m}$ and aspect ratios of 5:1-8:1, and interlock with high angles of more than $30^{\circ}$. These high-angle boundaries and intragranular high-density dislocation hinder crack propagation and reduce the tendency of cleavage. The diffraction pattern further confirmed that the microstructure is $\alpha$-Fe, as illustrated in Figs. 4(b) and 4(c).

\section{Conclusions}

(1) When welding heat input of $11 \mathrm{~kJ} / \mathrm{cm}$ to $20 \mathrm{~kJ} / \mathrm{cm}$ were undertaken without preheating treatment, the welding 
of low alloy high strength steels Q690 and Q550 can be realized with MK·G60-1wire by gas shielded arc welding process. The similar variation of crack ratio with heat input was present no matter which welding wire was used. The variation shows a trend of first decrease and then increase with the increase of heat input.

(2) Compared with the microstructure in weld metal with ER50-6 wire, the addition of $\mathrm{Ti}$ and $\mathrm{Cr}$ in $\mathrm{MK} \cdot \mathrm{G} 60-1$ wire suppressed the formation of pro-eutectoid ferrite and ferrite side plate and yet increase the amount of acicular ferrite. The refined microstructure in weld metal with MK·G60-1 wire contributed to high impact toughness of weld metal.

(3) In weld metal with MK·G60-1 wire, the combination of ( $\mathrm{Ti}, \mathrm{Mn}$ ) oxides and $\mathrm{Mn}, \mathrm{Cu}$ sulfides can act as active nucleation sites of primary acicular ferrite, and furthermore these primary ferrite plates can autocatalytically nucleate secondary acicular ferrite. Both nucleation on inclusions and autocatalytic nucleation on pre-existing ferrite plates play a significant role in the formation of acicular ferrite.

\section{REFERENCES}

1) M. Díaz-Fuentes, A. Iza-Mendia and I. Gutiérrez: Metall. Mater. Trans. A, 34 (2003), 2505.

2) G. Thewlis: Mater. Sci. Technol., 20 (2004), 143.

3) S. Ogibayashi: Nippon Steel Tech. Rep., 61 (1994), 70.

4) H. K. Sung, S. Y. Shin, W. Cha, K. Oh, S. Lee and N. J. Kim: Mater. Sci. Eng. A, $\mathbf{5 2 8}$ (2011), 3350.

5) B. Beidokhti, A. H. Koukabi and A. Dolati: Mater. Charact., 60 (2009), 225.

6) J. M. Gregg and H. K. D. H. Bhadeshia: Acta Mater., 45 (1997), 739.

7) M. Wakoh, T. Sawai and S. Mizoguchi: ISIJ Int., 36 (1996), 1014.

8) T. Sawai, M. Wakoh, Y. Ueshima and S. Mizoguchi: ISIJ Int., 32 (1992), 169.

9) G. Magudeeswaran, V. Balasubramanian and G. Madhusudhan Reddy: J. Mater. Eng. Perform., 18 (2009), 49.

10) D. L. Ren, F. R. Xiao, P. Tian, X. Wang and B. Liao: Int. J. Miner. Metall. Mater., 16 (2009), 65.

11) J.-S. Byun, J.-H. Shim, Y. W. Cho and D. N. Lee: Acta Mater., 51 (2003), 1593.

12) S. S. Bahu: Curr. Opin. Solid State Mater. Sci., 8 (2004), 267.

13) J. C. F. Jorge, L. F. G. Souza and J. M. A. Rebello: Mater. Charact., 47 (2001), 195.

14) W. Y. Choo and J. Y. Lee: Metall. Mater. Trans. A, 13 (1982), 135. 